Afrah K Al -Hamadani BDS, MSc (Asst Prof.)

Enas T Al-Jwary BDS, MSc (Lec.)

\section{Effect of Artificial Salvia on Force Values of Two Types of Nickel Titanium Ortho- dontic Arch Wires}

\author{
Dept of Pedod, orthod, and Prev Dentistry \\ College of Dentistry, University of Mosul \\ Dept of Pedod, orthod, and Prev Dentistry \\ College of Dentistry, University of Mosul
}

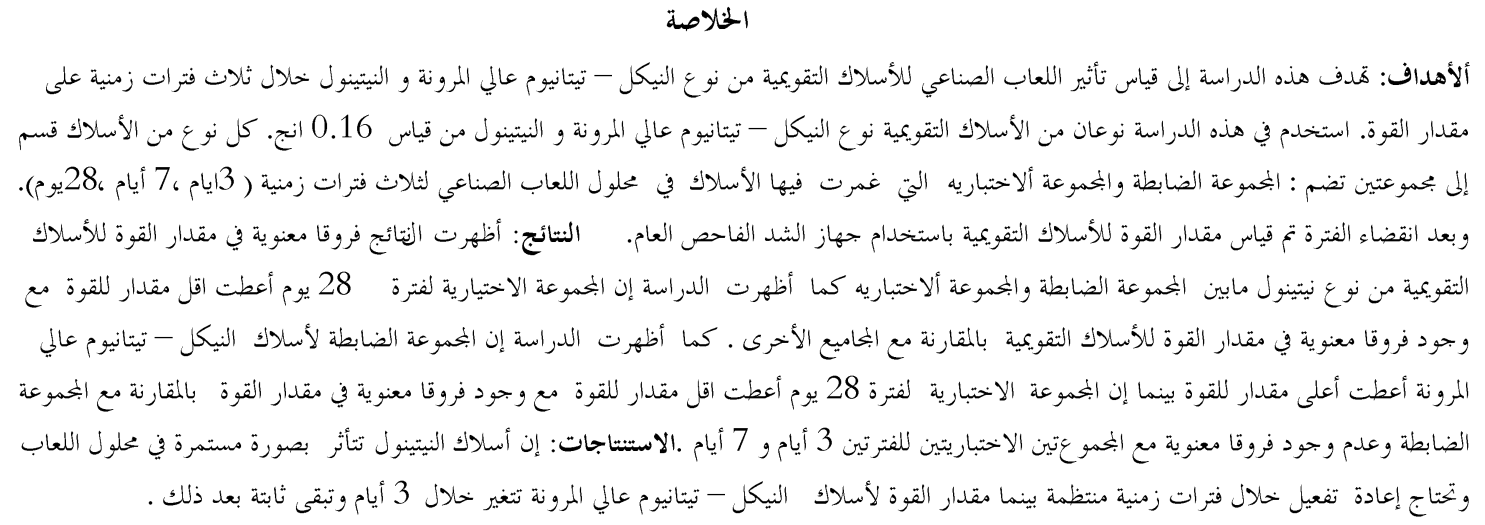

\title{
ABSTRACT
}

Aims: To study the effect of artificial saliva and time interval on the amount of force values of nitinol and superelastic NiTi wires. Materials and Methods: Two types of orthodontic wires chosen for the study nitinol and superelastic NiTi wires of a guage of 0.016 inch in diameter (Dentaurum, Germany). Specimens of the wires were divided in to two groups ; the control group(dry condition) contained the wires as - received condition and experimental groups for the study of the force value of wires which subjected to artificial saliva for three time incubation periods (3 days, 7 days, 28 days). At end of each incubation periods, the wire specimens were tested for the effect of artificial saliva on force values of the wire. The measurement of force values of arch wires done with a universal tensile testing machine ,the force values of specimens were evaluated with the help of three point bending test. The results were subjected to the descriptive statistics and to the ANOVA and Duncan's Multiple Range Analysis Tests to detect the amount of changes among these groups . Result: The findings of the present study showed that the control group of nitinol wires had the highest rate of force value with significant difference $(P \leq 0.05)$ with experimental groups, while the experimental group after 28 days gave rise to the lowest one with significant difference $(P \leq 0.05)$ from other groups. For the superelastic nickel titanium the result showed that the control group had the highest rate of force value while the experimental group after 28 days gave rise to the lowest one with significant difference $(P \leq 0.05)$ from control and non significant difference $(P>0.05)$ with the experimental groups after 3 days and 7 days. Conclusion: The nitinol wires showed a continuous change in force values with increase time in artificial saliva, so this required reactivating or changing the wire at a certain interval of use. While force values of the superelastic nickel titanium wires decreased after 3 days interval and remained constant after that .

Keywords: Artificial Salvia, Nickel Titanium Wires, Force value

Al -Hamadani AK, Al-Jwary ET. Effect of Artificial Salvia on Force Values of Two Types of Nickel Titanium Orthodontic Arch Wires. Al-Rafidain Dent J. 2012; 12(2): 301-308.

Received: 13/3/2011 Sent to Referees: $17 / 3 / 2011 \quad$ Accepted for Publication: 10/5/2011

\section{INTRODUCTION}

A vital component of the fixed orthodontic appliance is the orthodontic arch wire. ${ }^{(1,2)}$ Recent advances in orthodontic wire alloys have resulted in a varied array of wires and these include stainless steel, cobalt chromium, nickel - titanium, beta titanium and multistranded stainless steel wires. ${ }^{(3)}$ In early 1960s, a nickel-titanium alloy was developed by W. F. Buchler at USA Naval Ordnance Laboratory in Silver Springs. ${ }^{(4)}$ The first nickel-titanium alloy 
known as nitinol, the name nitinol was derived from Nicket- Titanium Naval Ordinance Laboratory. ${ }^{(5)}$ Evans and Durning $(1996)^{(6)}$ stated that there are three types of commercially available nickel titanium wire:

\section{- Martensitic Stable (conventional} Alloy)

- Austenitic Active (Pseudo-elastic) elastic)

- Martensitic Active (Thermo-

Intra-orally placed materials (i.e. wires, brackets) exhibit a pattern of continuous reaction with the environmental factors present in the open oral cavity. ${ }^{(7-8)}$ These environmental conditions of the oral cavity might alter the morphological, structural and compositional characteristics, force delivery of archwires, superelasticity and fracture of orthodontic alloy. ${ }^{(9)}$

These oral environments include saliva, acids arising from degradation and decomposition of food $(\mathrm{PH})$, oral flora and its by products, temperature change and stress. ${ }^{(10,12)}$ The quantity and quality of saliva may influence corrosion. ${ }^{(13,14)}$ The anticorrosion properties of nickel - titanium arch wires are due to the formation of oxide layers on the surface of alloys, which inhibit further corrosion. On Ti alloys several oxides are formed upon exposure to air, including $\mathrm{TiO}_{2}, \mathrm{TiO}$ and $\mathrm{Ti}_{2} \mathrm{O}_{5}$ with $\mathrm{TiO}_{2}$ being the most dominant. ${ }^{(7,15)}$ The $\mathrm{Ti}$ oxide layer formed on titanium alloys such as the NiTi wires is more stable than the chromium oxide, particularly in environments containing chloride anions. ${ }^{(16)}$ So, the general mechanism for the corrosion and subsequent release of metal ion involve the loss of passivated layer (oxide layer) so when the oxide layer dissolve, the onset of surface corrosion begins. ${ }^{(17)}$

\section{MATERIALS AND METHODS}

Two types of orthodontic wires were taken included nitinol and superelastic NiTi wires(Dentaurum, Germany). The 0.016 inch wires were selected because its popularity with the clinicians for initial leveling and aligning and because these are the most likely wires to be recycled. ${ }^{(18)}$ The specimens' length of the archwires used in this study was $50 \mathrm{~mm} .{ }^{(19)}$ These specimens of the wires were divided in to two groups ;the control group contained the wires as - received condition (dry condition) and experimental groups for the study of the force values of wires which subjected to artificial saliva for three time intervals ( 3 days, 7 days, 28 days). The formula used for preparation of artificial saliva solution was described by Barrett et $a l .{ }^{(20)}$ and this includes: $0.4 \mathrm{gm} \mathrm{NaCl}, 1.21$ gm $\mathrm{KCl}, 0.78$ gm $\mathrm{NaH}_{2} \mathrm{PO}_{4} .2 \mathrm{H}_{2} \mathrm{O}$, $0.005 \mathrm{gm} \quad \mathrm{Na}_{2} \mathrm{~S} .9 \mathrm{H}_{2} \mathrm{O}, \quad 1 \mathrm{gm}$ urea $\left[\mathrm{CO}\left(\mathrm{NH}_{2}\right)_{2}\right]$ and $1000 \mathrm{ml}$ distilled and deionized water.The $\mathrm{PH}$ of the artificial saliva was adjusted by using $\mathrm{pH}$ meter to $6.75 \pm 0.15$ with $10 \mathrm{~N}$ sodium hydroxide. The $\mathrm{pH}$ value was coincided with that reported for human saliva. The wires engaged in the acrylic models as in Figure (1) in which three brackets fixed with a light cure composite resin (XRV Herculite). The standard edgewise stainless steel brackets $(0.018 \times 0.030$ inch $)$ fixed in about five $\mathrm{mm}$ inter proximally and three millimeters infero -superior discrepancy between the center bracket and the adjacent one .This distance determines the amount of displacement of wires. As described by Burstone et al. ${ }^{(21)}$

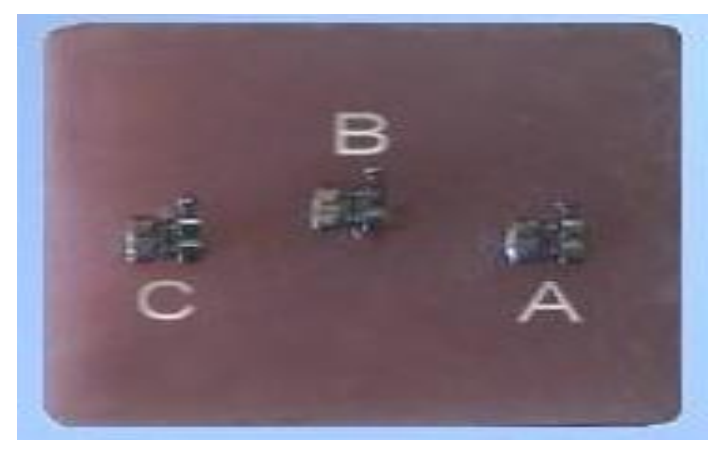

Figure (1): Acrylic Block on which a Standard Stainless steel Brackets Fixed. 
After that the specimen of each wire type was then taken and secured to brackets on acrylic block by ligature elastics, so the wire subjected to $3 \mathrm{~mm}$ deflection, ten blocks made and then the samples put in a closely packed glass container and $200 \mathrm{ml}$ artificial saliva added to them, the samples were stored in incubator at $37{ }^{\circ} \mathrm{C}$. At end of each incubation periods ( 3 days, 7 days, 28 days), the wire specimens were taken to study the effect of artificial saliva on force values of the wire. The measurement of force of archwires was done with a sal tensile testing machine (FestigkeitsPrufmaschine F 410, Germany) Figure( 2) with a full scale range of $2000 \mathrm{gm}$ in a 5 gm graduation.

The force values of specimens were evaluated with the help of three point bending test as described by Miura et al. , and Taneja et al. ${ }^{(19,22)}$ A three point bending test was performed on the especially designed fixture Figure (3) which was prepared according to the design described by previous studies by Miura et al and Krishnan and Kumar. ${ }^{(22,23)}$

The wire specimen is attached to the brackets on the two poles Figure (3) by ligature elastics (Orthomatrix, USA). The stage of single pole was attached to a movable head of a universal tensile testing machine, so that the single pole was on the center of the wire span. The mid portion of the wire was then deflected by the pressure of the single pole with a cross head speed of $0.5 \mathrm{~mm} / \mathrm{sec}$ and the force value was measured at each deflection distance; So ten wires of each type were measured during loading (activation) of wires to $3 \mathrm{~mm}$ deflections. All the tests were performed at room temperature at $30 \pm 0.5^{\circ} \mathrm{C}$. The statistical analysis used in this study includes descriptive statistics to show mean, standard deviation and standard error for each.

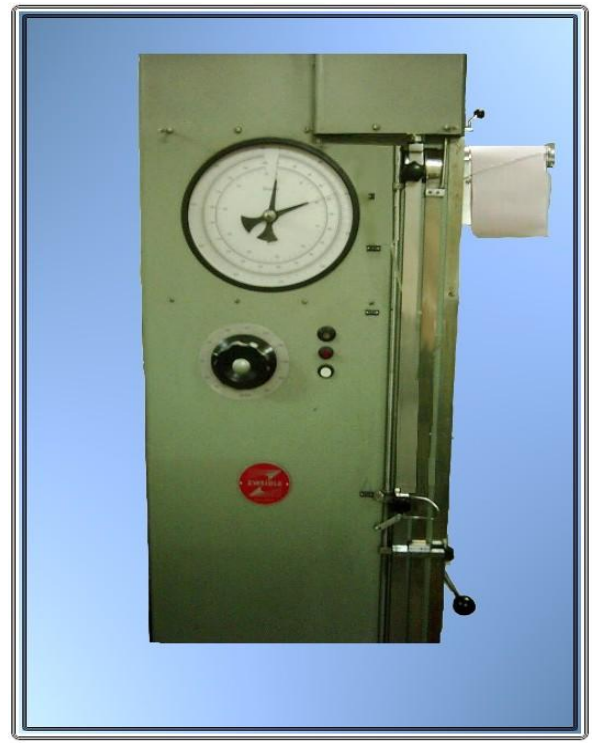

Figure(2) : Universal Tensile Testing Machine

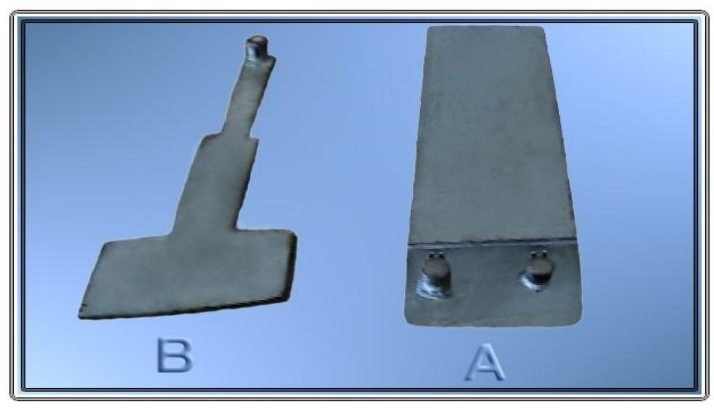

Figure (3): Special Design Fixture

Analysis of variance (ANOVA) was used to assess the significant difference among the groups at 0.01 of significance level. Duncan's Multiple Range Test was used to locate the significant differences among the groups at 0.05 significant level.

\section{RESULTS}

Effect of artificial saliva on force values of nitinol wire: The descriptive statistics that include mean, standard deviation, standard error, minimum and maximum values of force rate related to gram (gm) at $3 \mathrm{~mm}$ deflection during loading for control and experimental groups are listed in (Table 1). 
Table (1): Descriptive statistics demonstrate loading force (gm) at $3 \mathrm{~mm}$ deflection of nitinol wire after subjected to artificial saliva.

\begin{tabular}{lcccccc}
\hline Groups & No. & Mean & $\begin{array}{l}\text { Standard } \\
\text { Error }\end{array}$ & $\begin{array}{l}\text { Standard } \\
\text { Deviation }\end{array}$ & Minimum & Maximum \\
\hline Control & 10 & 424.000 & 0.666 & 2.108 & 420.000 & 425.000 \\
Experimental after 3 days & 10 & 409.000 & 0.666 & 2.108 & 405.000 & 410.000 \\
Experimental after 7 days & 10 & 389.000 & 0.666 & 2.108 & 385.000 & 390.000 \\
Experimental after 28days & 10 & 344.000 & 0.666 & 2.108 & 340.000 & 345.000 \\
Total & 40 & 391.500 & 4.831 & 30.554 & 340.000 & 425.000 \\
\hline
\end{tabular}

The findings of the present study showed that the control group gave rise to the highest mean values of force rate while the experimental group after 28 days gave rise to the lowest one. The one way analy- sis of variance (ANOVA) for the force value of wire among control and experimental groups showed significant difference $(P<0.001)$ among them as in (Table 2).

Table (2): (ANOVA) for Statistics Demonstrate Loading Force (gm) at $3 \mathrm{~mm}$ Deflection of Nitinol Wire After Subjected to Artificial Saliva.

\begin{tabular}{llllll}
\hline & Sum of Square & df & F- value & Mean Square & $\boldsymbol{P}$ \\
\hline $\begin{array}{l}\text { Between } \\
\text { groups }\end{array}$ & 36250.0 & 3 & & 12083.333 & \\
$\begin{array}{l}\text { Within } \\
\text { groups }\end{array}$ & 160.0 & 36 & 2718.750 & 4.444 & $P<0.001$ \\
Total & 36410.0 & 39 & & & \\
\hline
\end{tabular}

The result of Duncan's multiple range test (Table 3) showed that the control group had the highest rate of force value with a significant difference $(P \leq 0.05)$ when compared with experimental groups, while the experimental group after 28 days gave rise to the lowest one with significant difference $(P \leq 0.05)$ from other groups.

Table (3): Duncan's Multiple Range Test for Statistics Demonstrate Loading Force (gm) at $3 \mathrm{~mm}$ Deflection of Nitinol Wire after Subjected to Artificial Saliva.

\begin{tabular}{cccc}
\hline Groups & No. & Mean \pm SE (Force in gm) & $\begin{array}{c}\text { Duncan } \\
\text { Groups* }\end{array}$ \\
\hline $\begin{array}{c}\text { Control } \\
\text { Experimental after 3 } \\
\text { days }\end{array}$ & 10 & $424.000 \pm 0.666$ & $\mathrm{a}$ \\
$\begin{array}{c}\text { Experimental after 7 } \\
\text { days }\end{array}$ & 10 & $409.000 \pm 0.666$ & $\mathrm{~b}$ \\
$\begin{array}{c}\text { Experimental after 28 } \\
\text { days }\end{array}$ & 10 & $344.000 \pm 0.666 \pm 0.666$ & $\mathrm{c}$ \\
\hline
\end{tabular}

* Different litters mean significant difference $(P \leq 0.05)$.

Effect of artificial saliva on force values of superelastic wire: The descriptive statistics that include mean, standard deviation, standard error, minimum and maxi- mum values of force rate related to gram $(\mathrm{gm})$ at $3 \mathrm{~mm}$ deflection during loading for control and experimental groups are listed in (Table 4). 
Table (4): Descriptive Statistics Demonstrate Loading Force (gm) at $3 \mathrm{~mm}$ Deflection of Superelastic Nickel- Titanium Wire After Subjected to Artificial Saliva.

\begin{tabular}{ccccccc}
\hline Groups & No. & Mean & $\begin{array}{c}\text { Standard } \\
\text { Deviation }\end{array}$ & $\begin{array}{l}\text { Standard } \\
\text { Error }\end{array}$ & Minimum & Maximum \\
\hline $\begin{array}{c}\text { Control } \\
\text { Experimental }\end{array}$ & 10 & 401.000 & 2.108 & 0.666 & 400.000 & 405.000 \\
after 3 days & 10 & 395.500 & 2.108 & 0.666 & 395.500 & 400.000 \\
$\begin{array}{c}\text { Experimental } \\
\text { after 7 days }\end{array}$ & 10 & 395.000 & 0.000 & 0.000 & 395.000 & 395.000 \\
$\begin{array}{c}\text { Experimental } \\
\text { after 28 days }\end{array}$ & 10 & 395.000 & 0.000 & 0.000 & 395.000 & 395.000 \\
Total & 40 & 398.000 & 3.358 & 0.531 & 395.000 & 405.000 \\
\hline
\end{tabular}

The findings of the present study showed that the control group gave rise to the highest mean of force, while the experimental groups gave rise to lowest one. The one way analysis of variance (ANO-
VA) for the force value of wire between control and experimental groups showed significant difference $(P<0.001)$ among them as in (Table 5).

Table (5): (ANOVA) for Statistics Demonstrate Loading Force (gm) at $3 \mathrm{~mm}$ Deflection of Superelastic Nickel- Titanium Wire After Subjected to Artificial Saliva.

\begin{tabular}{cclccc}
\hline & Sum of Square & df & Mean Square & F- value & $\boldsymbol{P}$ \\
\hline Between groups & 360.0 & 3 & 120.000 & & \\
Within groups & 80.0 & 36 & 2.222 & 54.000 & $P<0.001$ \\
Total & 440.0 & 39 & & & \\
\hline
\end{tabular}

The result of Duncan's multiple range test (Table 6) showed that the control group had the highest rate of force value with significant difference $(P \leq 0.05)$ with other groups while the experimental group after 28 days gave rise to the lowest one with significant difference $(P \leq 0.05)$ from control and non significant difference $(P>$ $0.05)$ with the experimental groups after 3 days and 7 days.

Table (6): Duncan's Multiple Range Test for Statistics Demonstrate Loading Force (gm) at 3 mm Deflection of Superelastic Nickel- Titanium Wire After Subjected to Artificial Saliva.

\begin{tabular}{cccc}
\hline Groups & No. & Mean \pm SE (Force in gm) & Duncan Groups* \\
\hline Control & 10 & $401.000 \pm 0.666$ & $\mathrm{a}$ \\
Experimental after 3 days & 10 & $395.500 \pm 0.666$ & $\mathrm{~B}$ \\
Experimental after 7 days & 10 & $395.000 \pm 0.000$ & $\mathrm{~b}$ \\
Experimental after 28 days & 10 & $395.000 \pm 0.000$ & $\mathrm{~b}$ \\
\hline
\end{tabular}

* Different litters mean significant difference $(P \leq 0.05)$.

\section{DISCUSSION}

The Effect of Artificial Saliva on force value on nitinol wire: The results of the present study showed that the control group (dry condition) displayed a significantly higher force value during loading than the experimental groups and this finding is similar to the result obtained by Harris et $a l .{ }^{(24)}$ who attributed this finding to corrosive attack in chloride environment, this attack was a pitting type of corrosion that affect the surface of the wires and result in degradation of their mechanical properties, so the long term use of nitinol wire would appear to be associated with decreased performance of the wire particularly the elasticity of the wire. A similar result was reported by Kapila et al. ${ }^{(25)}$ who found that when nitinol wire is subjected to clinical use it demonstrates a significantly lower force during loading than control group. Also, Lee and Chang ${ }^{(26)}$ concluded that the martenistic nickel titanium wire demonstrated a significant change in force values of recycle wire. 
This result was not coincident with Sarkar and Schwaninger ${ }^{(27)}$ who found that there was no change in force values and mechanical properties of nitinol after long term immersion in a $1 \%$ sodium chloride solution. In their study, Smith et al. ${ }^{(18)}$ reported that no clinically significant difference in force values between as - received and used wires and they suggested that the NiTi wire could be recycled at least once.

The Effect of Artificial Saliva on force value on Superelastic Nickel - Titanium Wire:

The results of the present study showed that the control group displayed a significantly higher force value during loading than the experimental groups and this finding was similar to the result obtained by Tang et al. ${ }^{(28)}$ who found that the superelastic wire suffered degradation of their mechanical properties and that the force generation capacity decreased in oral environment. It was also supported by Kapila et al. ${ }^{(25)}$ who displayed that the recycled NiTi wires were associated with reduced forces during loading and unloading than control wire and this was attributed to the increased pitting corrosion of the wire after clinical exposure and the authors concluded that alteration in characteristic of NiTi wire require more frequent activations or earlier arch wire changes than would normally be expected with control wires. Eliades and Bourauel ${ }^{(9)}$ stated that the intraoral exposure of NiTi wires alter the structure of alloy through surface attack in the form of pitting and crevice corrosion and these structural changes might have a potent effect on the mechanical performance of the material. In addition, this result agreed with Kapila and Sachdeva ${ }^{(3)}$ who observed a change in the characteristics of the 3 - point bending test after placing NiTi wires in vivo.

On the other hand, the present finding disagrees with Lee and Chang ${ }^{(26,29)}$ who reported that the superelastic NiTi wire demonstrated no significant change in the mechanical properties after clinical recycling. It also disagrees with Han and Quick and Benyahia et al, Fragou and Eliades $^{(30,32)}$ who stated that the superelastic was highly resistant to degradation of mechanical properties in stimulated oral environment and this would appear to present a distinct clinical advantage.

The results of the present study showed that all experimental groups displayed non significant differences in force values at those three times intervals and this may attributed to the formation of a stable passive oxide layer $\left(\mathrm{TiO}_{2}\right)$ Bentahar et $a l^{(33)}$ and Al-Joboury ${ }^{(34)}$, while Wever et $a l .{ }^{(35)}$ found that the daily released of nickel from NiTi alloy is strongly decreased after the first day of soaking. In addition, this result was attributed to the ability of NiTi alloy to be repassivated. A study conducted by Cioffi et al. ${ }^{(36)}$ showed that NiTi surface was composed of titanium oxide and nickel oxides and nickel might dissolved more easily than the titanium because its oxide which is not stable. So after some initial dissolution of nickel from the surface, the NiTi alloy might eventually repassivated forming a surface containing mainly titanium oxide in outer layer and nickel oxide in inner layer.

\section{CONCLUSION}

The artificial saliva was significantly affect the force values of the two types of the nickel titanium wires and there was a significant decrease in force values. The nitinol wire showed a continuous change in force values with increase the immersion time in artificial saliva, so this required reactivating or changing the wire at a certain interval of use. While superelastic nickel titanium showed a constant force value with increase the immersion time in artificial saliva and this was attributed to the formation of a stable passive oxide layer $\left(\mathrm{TiO}_{2}\right)$.

\section{REFERENCES}

1. Gurgel J, Kerr S, Powers JM, Lecrone V. Force deflection properties of superelastic nickel - titanium archwires. Am J Orthod Dentofac Orthop. 2001; 120(4): 378-382.

2. Laino G, Santis RD, Gloria A, Russo T, Quintanilla DS, Laino A, Martina R, Nicolais L, Ambrosio L. Calorimetric and Thermomechanical Properties of Titanium-Based Orthodontic Wires: DSCDMA Relationship to Predict the Elastic Modulus. J Biomater Appl. 2011, Feb: 22. 
3. Kapila S and Sachdeva R. Mechanical properties and clinical application of orthodontic wires. Am J Orthod Dentofac Orthop. 1989; 96(2): 100-109.

4. Kusy PR. Orthodontic biomaterials: from the past to the present. Angle Orthod. 2002; 72(6): 501-512.

5. Hurst CL, Manville GD, Nanda SR, Angolkar PV .An evaluation of the shape memory phenomenon of nickel-titanium orthodontic wires. Am J Orthod Dentofac Orthop. 1990; 98(1): 172-178.

6. Evans TJ and Durning P. Aligning archwires, the shape of things to come? A fourth and fifth phase of face delivery. Brit J Orthod. 1996; 23 (3): 269-275.

7. Eliades $\mathrm{T}$ and Athanasiou AE. In vivo aging of orthodontic alloys: implication for corrosion potential, nickel release and biocompatibility. Angle Orthod. 2002; 72(3): 222-237.

8. Daems J, Celis JP, Willems G . Morphological characterization of as-received and in vivo orthodontic stainless steel arch wires. Eur J Orthod. 2009, Jun; 31(3): 260-5.

9. Eliades $\mathrm{T}$ and Bourauel $\mathrm{C}$. Intraoral aging of orthodontic materials: the picture we miss and its clinical relevance. Am J Orthod Dentofac Orthop. 2005; 127(4): 403412.

10. Gioka C, Bourauel C, Zinelis S, Eliades T, Eliades G. Titanium orthodontic brackets: structure, composition, hardness and ionic release. Dent Materials. 2004; 20(7): 693-700.

11. Segal N, Hell J, Berzins DW. Influence of stress and phase on corrosion of a super elastic nickel-titanium orthodontic wire. Am J Orthod Dentofacial Orthop. 2009; Jun; 135(6): 764-70.

12. Bahije L, Benyahia H, El Hamzaoui S, Ebn Touhami M, Bengueddour R, Rerhrhaye W, Abdallaoui F, Zaoui F. Behavior of NiTi in the presence of oral bacteria: Corrosion by Streptococcus mutans. Int Orthod. 2011; Jan: 24.

13. Kim $\mathrm{H}$ and Johnson JW. Corrosion of stainless steel, nickel titanium, coated nickel titanium and titanium orthodontic wires. Angle Orthod. 1999; 69(1): 39-44.

14. Lee TH, Huang TK, Lin SY, Chen LK, Chou MY, Huang HH. Corrosion resistance of different nickel-titanium arch wires in acidic fluoride-containing artifi- cial saliva. Angle Orthod. 2010 May; 80(3): 547-53.

15. Iijima M, Yuasa T, Endo K, Muguruma T, Ohno H, Mizoguchi I. Corrosion behavior of ion implanted nickel-titanium orthodontic wire in fluoride mouth rinse solutions. Dent Mater J. 2010; Jan 29(1):538.

16. Medawar EL, Rocher P, Hornez JC, Traisnel M, Breme J, Hildebrand HF. Electrochemical and cytocompatibility assessment of nitinol memory shape alloy for orthodontic use. Biomolecular Engineering. 2002; 19(2-6): 153-160.

17. Petoumeno E, Kislyuk M, Hoederath H, Keilig L, Bourauel C, Jäger A. Corrosion susceptibility and nickel release of nickel titanium wires during clinical application. J Orofac Orthop. 2008 Nov; 69(6): 41123.

18. Smith GA, Fraunhofer JA, Casey GR. The effect of clinical use and sterilization on selected orthodontic arch wires. Am J Orthod Dentofac Orthop. 1992; 102(2): 153-159

19. Taneja P, Duncanson MG, Khajotia SS, Nanda RS. Deactivation force deflection behavior of multistranded stainless steel wires. Am J Orthod Dentofac Orthop. 2003 ; 124(1): 61-68

20. Barrett RD, Bishara SE, Janice KQ. Biodegradation of orthodontic appliances: part I- Biodegradation of nickel and chrominum in vitro. Am $\mathrm{J}$ Orthod Dentofac Orthop. 1993; 103(1): 8-14.

21. Burstone CJ, Qin B, Morton JY . Chinese NiTi wire: A new orthodontic alloy. Am J Orthod Dentofac Orthop. 1985; 87(6): 445-452.

22. Miura F, Mogi M, Ohura Y, Hamanaka H . The super elastic property of the Japanese NiTi alloy wire for use in orthodontics. Am J Orthod Dentofac Orthop. 1986; 90(1): 1-10.

23.Krishnan V and Kumar KJ. Mechanical properties and surface characteristics of three arch wire alloys. Angle Orthod. 2004;74(6): 823-829.

24. Harris EF, Newman SW, Nicholson JA. Nitinol archwire in a simulated oral environment: Changes in mechanical properties. Am J Orthod Dentofac Orthop. 1988; 93(6): 508-513.

25. Kapila S, Haugen JW, Watanabe L. Load deflection characteristics of nickel - tita- 
nium alloy wires after clinical recycling and dry heat sterilization. Am J Orthod Dentofac Orthop. 1992; 102(2): 120-126.

26. Lee SH and Chang YH. Three point bending test of recycled nickel - titanium alloy wires. J Korean Orthod. 2000; 30(4): 731-738.

27. Sarkar NK and Schwaninger B. The in vivo corrosion of nitinol wire. J Dent Res. 1980; 59 (Special issue A): 528-535.

28. Tang GH, Liu K, Cao HJ, Lu J, Zhang $\mathrm{CW}$. Orthodontic wires in a simulated oral environment, changes in mechanical properties. Shanghai Kou Qiang Yi Xue. 1997; 6(3): 159-162.

29. Lee SH and Chang YH. Effect of recycling on the mechanical properties and the surface topography of nickel - titanium alloy wires. Am J Orthod Dentofac Orthop. 2001; 120(6): 654-663.

30. Han S and Quick DC. Nickel - titanium spring properties in a simulated oral environment. Angle Orthod. 1993; 63(1): 6772.

31. Benyahia H, Ebntouhami M, Forsal I, Zaoui F, Aalloula E. Corrosion resistance of NiTi in fluoride and acid environments. Int Orthod. 2009 Dec; 7(4): 322-34.
32. Fragou S, Eliades T. Effect of topical fluoride application on titanium alloys: a review of effects and clinical implications. Pediatr Dent. 2010 Mar-Apr; 32(2): 99105.

33. Bentahar Z, Bellamine M, Zertoubi M, Irhzo A, El Boussiri K. Relationship between electrochemical corrosion and the tribologic properties of orthodontic alloys. Int Orthod. 2010 Dec; 8(4):360-71.

34. Al-Joboury HM. The corrosion behavior and the biological effect of fixed orthodontic appliance in artificial saliva solution (in vitro study) 2001. M.Sc. Thesis, College of Dentistry, Baghdad University.

35. Wever DJ, Veldhuizen AG, De Vries J, Busscher HJ, Uges DRA, Van Horn JR. Electrochemical and surface characterization a nickel - titanium alloy. Biomaterials. 1998; 19(7-9): 761-769.

36. Cioffi M, Gilliland D, Ceccone G, Chiesa R, Cigada A. Electrochemical release testing of nickel - titanium orthodontic wires in artificial saliva using thin layer activation. Acta Biomateriala. 2005; 1(6): 717 724. 